\title{
Industry architecture as a determinant of successful platform strategies: a case study of the i- mode mobile Internet service
}

\author{
Richard Tee, Annabelle Gawer \\ Imperial College Business School, London, UK. \\ Correspondence: \\ Richard Tee \\ Imperial College Business School \\ South Kensington Campus \\ Tanaka Building, London, SW7 2AZ, UK. \\ Tel: p44 (0) 207594 5928/1916; \\ Fax: p44 (0) 207594 5915; \\ E-mails: r.tee07@imperial.ac.uk, a.gawer@imperial.ac.uk
}

\begin{abstract}
What factors and processes drive value appropriation and value creation in interdependent industry ecosystems? This paper explores this issue through a case study comparing the deployment of the imode mobile Internet service in two countries, seeking the reasons behind its contrasting fortunes: spectacular success in Japan vs failure in Europe. The comparison between network operators NTT Docomo in Japan and KPN in the Netherlands suggests that differences in the underlying industry architectures explain why similar platform strategies led to such different outcomes. The paper contributes to the literature on industry architecture by unpacking the interaction between evolutionary processes, industry architecture, and business strategies. It also contributes to the platforms literature, by positing that firms' ability to successfully pursue platform strategies depends on industry architecture.
\end{abstract}

European Management Review (2009) 6, 217-232. doi:10.1057/emr.2009.22

Keywords: platform; platform leadership; industry architecture; architectural advantage; value creation; value appropriation; mobile telephony industry 


\section{Introduction}

To analyze firms' strategy and performance in their industrial context, management scholars have long represented relationships between firms in a given industry as a set of sequential, linear, supplier-buyer relationships, often referred to as a 'supply chain'. Observation of today’s complex high-tech industries however has brought to the fore the idea that in many cases, industries can be better analyzed as networks of interconnected firms or 'industry ecosystems' (Iansiti and Levien, 2004), to try to capture the multidimensionality and the complexity of firms' relationships. In this context, an important question is: What factors and processes drive value appropriation and value creation in interdependent industry ecosystems?

This paper explores this issue through a case study of i-mode, a mobile internet service created by Japanese mobile network operator NTT Docomo. I-mode provides a favorable context to explore this question, for three reasons. First, i-mode's setting constitutes an industry ecosystem, because imode was an innovation that was functionally dependent on a set of products, technologies and services developed by other firms. Second, i-mode is a platform, (Gawer and Cusumano, 2002, 2008), and as such, value creation and value capture are related in predictable ways: in particular, we know that platform firms cannot capture value without stimulating value creation by other members of the ecosystem. Third, the i-mode case presents us with a rich case of success and failure.

I-mode was a striking success in Japan, but subsequent attempts to commercialize it in Europe resulted in stark failure (Funk, 2001; Fransman, 2002; Steinbock, 2003; Haas, 2005; O’Brien, 2007). ${ }^{\text {i }}$ We analyze the deployment and commercialization of i-mode, and explore the reasons behind these contrasting outcomes, focusing on Japan and the Netherlands. I-mode's failure is particularly surprising considering that NTT Docomo had taken a $15 \%$ equity stake in KPN, the 
Dutch network operator deploying i-mode. KPN benefited from information sharing on i-mode technology and had privileged access to the original Japanese strategy.

The platform leadership literature (Gawer and Cusumano 2002, 2008), has explained the reasons behind i-mode's success in Japan, by positing that NTT Docomo had successfully pursued platform strategy aiming to stimulate and orchestrate ecosystem innovation. However, this literature does not explain why the same platform leadership strategy failed in the Netherlands. Our analysis suggests that the structural differences between Japan and the Netherlands in the rules and roles of industry actors, -- in other words, differences in "industry architecture" (Jacobides, Knudsen and Augier, 2006), -- were fundamental.

The architecture of the mobile telecom industry in the Netherlands constrained the capacity of the incumbent network operator to influence other key players in the industry ecosystem to provide essential complements such as i-mode-specific handsets and i-mode-compatible applications -- thus reducing i-mode's attractiveness to end-users. We therefore suggest that KPN failed in its attempt to achieve platform leadership because of differences in underlying industry architectures. Thus, our findings suggest that combining a platform approach with an industry architecture perspective offers useful insights for firms seeking platform leadership, and for scholars aiming to develop theory in these areas.

The success of NTT Docomo as a platform leader was predicated upon the successful integration of mobile phone technology and content, which were combined in an innovative business model that sustained its ecosystem of software developers, handsets manufacturers, and customers in a virtuous cycle. Compelling content (developed by external developers) attracted customers who in turn increased the installed base and therefore attracted more developers to the i-mode ecosystem, and 
also gave NTT Docomo the bargaining power to set specifications to handsets manufacturers. Ultimately, KPN was unable to replicate this strategy successfully.

Our data suggests that the processes of industry regulation and deregulation and the emergence of industry standards played out differently in these two countries, and that as a result the industries evolved differently. The industrial configurations in Japan and the Netherlands entailed different firms' scopes, which held different relationships with other firms, leading to different sets of firms' capabilities and degrees of bargaining power (this process is visually represented in figure 1). The combination of these factors fit well with the way Jacobides et al. (2006) conceptualize industry architecture.

[Insert figure 1 about here]

The architecture of the mobile telecom industry in the Netherlands fundamentally constrained the capacity of the incumbent network operator to influence other important players in its ecosystem to provide essential complements such as i-mode-specific handsets and compelling i-mode-compatible applications, hampering its attractiveness to end-users. It was the industry architecture that prevented KPN to successfully orchestrate ecosystem innovation around i-mode, and therefore prevented KPN to achieve platform leadership with i-mode in the Netherlands. While we are aware of the limitations of our study, which, given the nature of our data, can only offer exploratory results, this paper is, to our knowledge, the first empirical study to attempt to explore the interaction between industry architecture and industry platforms.

The paper is structured as follows. Following this introduction, we outline the concepts of platforms and industry architecture. Next, we briefly describe the methods we used and the type of data we gathered for the study. We subsequently describe the case evidence of i-mode's rollout in the 
context of the competitive dynamics of mobile telecom in Japan and the Netherlands. The following section offers our interpretation of the evidence. We conclude by presenting a discussion of our findings, indicate limitations of our study and point to directions for future research.

\section{Background Literature}

The empirical puzzle of i-mode's contrasting fortunes is connected to the broader theoretical issue of the dynamics of value appropriation and value creation in the context of interdependent economic systems. There is a rich literature exploring the factors driving firms' ability to benefit from innovation. Teece (1986) and the stream of innovation and strategy research his work inspired (such as Tripsas, 1997), have generally examined this question at the level of the dyad between firms, examining the competitive dynamics between innovators and their followers, or incumbents vs. new entrants. While a useful simplification, in reality, the context within which value is created and distributed often consists of network of interdependent actors. On the other hand, research that has focused at the industry level, such as work on industry evolution (see Klepper \& Graddy, 1990; Klepper \& Thompson, 2006) often takes a more structural approach, and tends to obscure the competitive dynamics associated with changing the logic of value creation and appropriation (see McGahan, 2004 for an exception). In recent years, two theoretical perspectives, industry architectures and platforms, have attempted to explicitly address the issue of how value is created as well as captured in the context of interdependent systems of firms and institutions.

\section{Industry Platforms}

Industry platforms are technological building blocks that act as a foundation upon which an array of firms, organized in a set of interdependent firms (sometimes called industry 'ecosystem'), develop a set of interrelated products, technologies, and services (Gawer, 2009a, 2009b). Platforms provide an essential, or 'core', function to an encompassing system-of-use. They are subject to so-called 
network effects, which tend to reinforce in a cumulative manner early-gained advantages such as an installed base of users, or the existence of complementary products (Eisenmann, Parker, and Van Alstyne, 2006). These platforms typically emerge in the context of modular industries (Baldwin and Clark, 2000; Baldwin and Woodard, 2009) or industry ecosystems (Iansiti and Levien, 2004).

Research on industry platforms (Gawer and Cusumano, 2002, 2004, 2008) and ecosystems (Iansiti and Levien, 2004) builds on earlier research on technology evolution and technological dominance (Utterback and Abernathy, 1975; Tushman and Anderson, 1986; Suarez, 2004; Murmann and Frenken, 2006), as well as literature on standards and network externalities (Katz and Shapiro, 1985; Shapiro and Varian, 1998). It also draws on literature on engineering design, product architecture and modularity (Ulrich, 1995; Baldwin and Clark, 2000; Schilling, 2000), and research on new forms of industry dynamics mixing competition and cooperation (coined as 'co-opetition', see Brandenburger and Nalebuff, 1996) which highlight the importance of 'complementors' developers of complementary products and services.

Gawer and Cusumano (2002, 2004, 2008) have formulated strategies to allow firms to achieve platform leadership. 'Platform leaders' (Gawer and Cusumano, 2002; Cusumano and Gawer, 2002) are organizations that manage to successfully establish their product, service or technology as an industry platform. Platform leaders tend to drive industry-wide innovation in a trajectory that allows them to exert architectural control over the overall system, as well as derive large profits and erect barriers to entry in their own market.

Platform leaders are highly dependent on innovations developed by other firms, but, at the same time, aim to ensure the overall long-term technical integrity of the evolving technology platform (Gawer and Cusumano, 2002). Platform leaders aim to create innovation in complementary products and services, which in turn increase the value of their own product or service. At the same 
time, they wish to preserve or increase competition among complementor firms, thereby maintaining their bargaining power over complementors. Platform leadership is therefore always accompanied by some degree of architectural control. Further, the momentum created by the network effects between the platform and its complementary products or services can often erect a barrier to entry from potential platform competitors. As such, establishing an industry platform requires not only technical efforts to increase value creation opportunities for the ecosystem participants, but also establishing a business model that is sustainable for ecosystem participants.

\section{Industry Architectures}

Complementary to the research on platforms, a new strand of work centered on the notion of 'industry architecture' (Jacobides et al., 2006) has emerged. It focuses on the ways in which activities along the value chain get divided among industry participants, paying particular attention to firm roles, interdependencies and the ways in which organizations attempt to shape the industry's division of labor. The concept of industry architecture (Jacobides et al., 2006) defines the ways in which roles are distributed among interacting firms. Industries have fairly well established rules about what activities each party undertakes, as well as roles played by industry players. Industry architecture defines both the division of labor between firms and the division of surplus in industries, and provide the template for both "who does what" and "who gets what". Industry architectures are characterized the distinct ways in which industries follow particular rules and how firms' scope, roles, and relationships, account for the ways in which value gets both created and appropriated. Therefore, the concept of industry architecture echoes insights derived from institutional theory, invoking the informal "rules of the game" as well as the formal legal framework that industry participants need to adhere to. As such, an industry's intellectual property regime can have an important effect on industry architecture (Pisano \& Teece, 2007). Further, industry architecture has implications for the way firm capabilities are distributed within a particular industry (Jacobides \& Winter; 2005). Environmental shocks, such as changes in 
regulation, can lead to significant changes in the way an industry organizes itself, with important implications for control or profitability of particular types of firms (Cacciatori \& Jacobides, 2005; Jacobides, 2005).

Depending on the structure of the industry architecture, certain types of firms can capture more value than others. Jacobides et al (2006) suggest that this "architectural advantage" depends on two factors: complementarity and mobility of assets. Complementarity refers to the combined returns from the combination of two or more assets, with some combinations resulting in higher value creation than other combinations. Mobility concerns the number of assets that can potentially be combined to create such combinations, and switching costs of these assets should not be significant. Firms enjoy an architectural advantage when both factors are high. Recent contributions to the industry architecture literature include work by Ozcan and Eisenhardt (2009), who focus on network ties in relation to industry architecture formation; and Cowhey, Aronson and Richard (2008), who analyze the historical trajectories of technological networks in relation to industry architecture and public policy. As such, existing research on platforms and industry architecture has started to contribute to understanding how organizations influence the way work is divided among industry participants and its impact on value creation and value appropriation.

\section{Industry architecture and platforms: impact on value creation and value capture}

Research on industry platforms has highlighted the need to understand both the technological and business actions required to successfully establish a platform. It has highlighted the trade-offs between value creation and value appropriation resulting from product design choices such as those regarding opening or closing elements of the platform, as well as choices with regards to ecosystem governance. However, research in this area has largely been limited to the platform ecosystem itself, or to the interactions between different platform ecosystems. By contrast, research on industry architectures, which has emphasized how different actors' roles along the value chain 
affect the overall distribution of value, has not specifically focused on platform structures or ecosystem interactions; as such, it may offer insights that extend beyond the platform ecosystem. Furthermore, research in this area has investigated the underlying drivers affecting the distribution of these roles. Therefore, it may be suggested that industry architectures provide the broader conditions in which industry participants, including potential platform leaders and complementors, operate. In turn, these participants may have the ability to shape the industry architecture to their advantage. However, it is unclear how exactly platforms play a role in this process and if and how the industry architecture affects the ability of players to successfully implement well-formulated platform strategies.

The complementarity between the industry architecture perspective and the platform approach should not come as a complete surprise. Research on platforms and on industry architecture share common themes, as they both aim to contribute to understanding how organizations influence the way labor is divided among industry participants and its impact on value creation and value appropriation. Another common theme is the central role of the notion of 'architectural control', also referred to as a 'bottleneck' in the literature on industry architecture (Jacobides et al. 2006). As such, both research strands explore how different structural positions of firms affect value creation, profit and value distribution. They cover similar territories but approach them from different angles. While research on platform strategies has focused on the rewards associated with managerial action (some of these rewards having to do with establishing architectural control, leading to an ability to extract superior profits), the concept of industry architecture lends itself towards the examination of how embedded and sometimes implicit structures may limit the scope for managerial action. Research on industry architecture however also suggests that such architectures can be manipulated by deliberate, forward-looking firms (and in this case, these behaviors much resemble firms' attempts to establish platform leadership). At a more fundamental level, both platform literature and industry architecture literature grapple with the interaction between action and structure. 


\section{Data and Methods}

This paper followed a case-study methodology, testing and revising hypotheses throughout our data collection process (Eisenhardt, 1989; Yin, 2003). We collected data from written publications (industry publications, books and articles) and interviews, aiming to get a better understanding of 1) the process of designing and deploying the platform, and 2) the various actors and roles in the industry architecture, where we focused on understanding the vertical scope of the actors and their relationships to other actors. To ensure that we obtained multiple perspectives of our phenomenon of interest, we interviewed representatives from all relevant actors. We carried out 50 interviews in three different periods (2002, 2004 and 2009), carrying out 21 interviews in Japan and 29 in Europe. ${ }^{\text {ii }}$ The interviews followed a semi-structured protocol and lasted on average one hour. The first two sets of interviews were conducted face-to-face, while the last set was done via telephone. Interview reports were submitted to interviewees for verification. One of the authors presented intermediate findings at a conference targeted at industry and public policy makers, organized by one of the European i-mode operators, providing feedback on our initial findings. We tried to ensure triangulation of our data using these different sources of evidence.

\section{Choice of Country Comparator}

Following the success of i-mode in Japan, the service was deployed in over a dozen countries outside of Japan (Table 1 gives an overview of the European countries where the service was introduced).

[Insert Table 1]

The choice of the Dutch context for i-mode's commercialization was predicated upon its structural similarity with Japan, to the extent that the respective i-mode champions KPN and NTT Docomo 
were both market leaders, network operators, and incumbents. It might have been preferable, given the size of the domestic Japanese market, to have sought a comparison with the wider European market - but a single European market does not yet exist in telecommunications, since telecom regulations are still largely determined nationally and not at the European level. ${ }^{\text {iii }}$ Further, KPN was the first operator after NTT Docomo to introduce i-mode. As such, this comparison decreases the time difference of the introductions. Secondly, KPN, like NTT Docomo, was the incumbent operator and crucially, market leader when i-mode was introduced. This contrasts with the majority of other European i-mode operators, most of which were challengers. Third, among the various imode deployments outside of Japan, cooperation between NTT Docomo and KPN was arguably strongest, given the timing of the introduction and the financial stake NTT Docomo held in KPN at that time. As such, this choice reduces the influence of differences in e.g. strategy that may have otherwise impacted on the deployment of the service.

We did not choose to compare Japan with larger European countries (e.g. Germany, UK, France, Italy) for a number of country-specific reasons. In Germany, i-mode operator E-plus was a challenger; this also applies to Bouygues in France and WIND in Italy. In the UK, O2 might have been considered, though it was no longer the market leader when it licensed i-mode, and crucially, introduced the service more than six years after NTT Docomo. As such, choosing a mid-sized operator and market leader like KPN appears to be the most suitable choice. Of course important disparities between both countries remain, including population size, cultural differences, degree of Internet penetration, etc. Whilst recognizing the limitations introduced by these variations, we will argue that the overall patterns observed in the Netherlands can to a large extent also be applied to other European i-mode deployments, given similarities in industry architecture roles and conditions. 


\section{Case Evidence: I-mode Rollout and Industry Dynamics}

This section presents evidence on i-mode's rollout in Japan and in the Netherlands, and provides background on industry dynamics, including regulation and standardization.

I-mode is an example of a mobile Internet service, operating amongst a wider spectrum of offerings. In Europe, most network operators focused on delivering mobile Internet services via standard protocols, in particular WAP (Wireless Application Protocol) and MMS (Multimedia Messaging Service)_( (Sigurdsson, 2001; Steinbock, 2003). Later, i-mode came to encapsulate these standards into its offering. As such, i-mode provides a richer service than competing standards-based mobile Internet services (e.g. providing push email and instant messaging) - albeit at the cost of providing a narrower range of handsets. More recently, mobile Internet solutions have been provided as specialized email solutions (e.g., RIM's BlackBerry devices) or through mobile web browsers that make use of larger touch screen displays (popularized in Apple's iPhone). I-mode requires a network operator who needs to orchestrate the relevant content and services and make sure the mobile devices are aligned to these services. I-mode can therefore be construed as an operatorcentric solution to providing mobile Internet services. This might be contrasted with more recent business models, such as device-centric models exemplified by Apple's iPhone (Ballon, 2009)

I-mode was introduced in Japan in February 1999 and its subsequent success has been well documented (see Funk, 2001; Fransman, 2002; Steinbock, 2003; Gawer \& Cusumano 2002). In 2007, 48 million users out of NTT Docomo's 54 million subscribers used i-mode, $89 \%$ of their user base. I-mode's deployment outside of Japan has been very different. As of 2007, five years after the European roll-out started, initial i-mode providers have phased out the service. Compared to NTT Docomo, the difference in i-mode subscribers is especially striking, with no European operator having been able to reach more than $21 \%$ of their user base. Table 1 compares i-mode's Japanese deployment to Europe, identifying the time of introduction, number of subscribers, status of the 
service, and i-mode handset suppliers. In the following section we describe deployment process in more detail.

\section{I-mode's Rollout in Japan}

From i-mode inception in 1997, NTT Docomo made several decisions regarding its technical design as well as it business model, including its approach to content, handsets specifications and pricing. It used a revenue-sharing agreement to induce content provision and implemented a micropayment system where users were billed for the data they consumed. NTT Docomo would charge a 9\% transaction fee for monthly user fees, with the remaining $91 \%$ going to the content provider. The micropayment system could only be used by official i-mode content providers, who were linked from the i-mode home menu. These approved content providers needed to adhere to several rules, such as a limit on the monthly fee, and types of content. Handset makers were enlisted to design imode handsets, focusing on a uniform user interface, menu, and dedicated i-mode and mail buttons.

At the launch, only one i-mode handset was available, with 67 content providers having signed up. Three additional i-mode handsets were introduced soon after, whilst NTT Docomo continued to improve the platform's functionality. In contrast to expectations, entertainment (ringtones and screensavers) initially proved most popular, rather than more functional usage such as mobile banking or news (Funk, 2001). However, since the design of the platform facilitated fast and accurate feedback, the range of content could quickly be adjusted and rapid entry of additional content providers ensued. Following the success of i-mode, NTT Docomo subsequently made imode available via its $3 \mathrm{G}$ service FOMA, and later expanded into other services including mobile payments (FeliCa), mobile television (1seg), and music downloads. 


\section{I-mode's Rollout in the Netherlands}

KPN introduced i-mode in the Netherlands in April 2002, phasing out the service five years later. Discussions between NTT Docomo and KPN regarding cooperation started in the summer of 1999, about half a year after the Japanese launch. The companies were looking for ways to cooperate on mobile multimedia services. KPN organized several senior management level visits to Japan, as well as a visit of potential end-users to assess customer response. Given positive reception from both constituencies, KPN decided to pursue the opportunity. In May 2000, NTT Docomo took a $15 \%$ share in KPN mobile and in September 2000 the firms issued a licensing agreement to introduce "i-mode like" services. ${ }^{\text {iv }}$

NTT Docomo played an important role in KPN's launch of i-mode. For example, the Japanese firm trained and hired additional people so that they were able to cooperate effectively in English. It also made a number of considerable technical investments: for instance, since Japan used a different network standard than Europe, NTT Docomo decided to build a customized test network (based on the European GPRS standard) to be able to test and prototype handsets and services in Japan. NTT Docomo also helped with negotiating handsets, and was instrumental in acquiring the first GSMbased i-mode phone. Subsequent handsets, such as models from Samsung, were also procured with the assistance of NTT Docomo. Finally, KPN and NTT Docomo worked together to attract other operators to license i-mode. Following the bifurcation of the project, NTT Docomo subsequently located its European i-mode headquarters in the Netherlands. Concurrently, the KPN team worked on the design of the service. One important decision was which standards to include in translating NTT Docomo's Japanese i-mode specifications, in particular with regards to email and browsing functionality. Whereas NTT Docomo was used to being able to essentially prescribe its standards to handset makers (Funk, 2001), KPN felt it needed to adjust the specifications to the context of the GSM market. This meant that it tried to base content delivery specifications around WAP-OMA standards, so that handsets would be easier to customize to i-mode's requirements. Further, it was 
expected that the convergence towards a single $3 \mathrm{G}$ standard would also facilitate procurement of future Japanese 3G i-mode handsets.

In the buildup to the launch, a select group of pilot users responded largely positively to both the handset and the range of services. The accompanying handset was developed by NEC, an experienced Japanese handset maker, -- but an entrant to the GSM market. Further, KPN had enlisted over 50 i-mode content providers, covering a wide spectrum of well-known firms, including major newspapers, banks and entertainment providers. Media interest in i-mode was high. Still, in spite of high initial visibility and expectations, i-mode adoption was slower than expected. KPN had set a target of 1 million users by the end of 2003 - but failed to attain this (Van Impe, 2003).

One reason for slow i-mode adoption, in contrast to Japan, was that procurement of i-mode handsets proved to be more difficult than anticipated. At the outset, no major GSM handset maker was willing to develop a customized i-mode handset. As a result, KPN was initially dependent on Japanese handset makers who, with the help of NTT Docomo, were willing to develop customized i-mode handsets. However, their inexperience in developing handsets for the GSM market negatively affected the quality of the initial handsets (in terms of size, battery life etc). Further, KPN's expectation that Japanese 3G handsets might be procured more easily would not materialize. The differences between Japanese and European 3G handsets proved to be substantial, since handsets still required support for the different underlying $2 \mathrm{G}$ networks.

When faced with the lack of commitment from GSM vendors, KPN decided to loosen the i-mode specifications for handset makers. In contrast to the strict ways in which NTT Docomo was able to prescribe handset specifications in Japan, KPN introduced an additional class of handsets, which did not offer full i-mode functionality (for example in terms of email functionality), but were 
largely compatible with i-mode sites. Second, KPN and NTT Docomo also tried to address the issue of lack of volume by enlisting other operators to license i-mode. This group of operators joined forces in the i-mode alliance, sharing best practice, negotiating with content or marketing partners and developing technical specifications. ${ }^{\mathrm{v}}$ However, the most important goal was to increase bargaining power vis-à-vis leading handset makers, in particular the market leader Nokia. Even as the i-mode alliance expanded, the service would not reach the required scale to convince Nokia to develop dedicated i-mode handsets. NTT Docomo’s leverage in Japan eventually persuaded Samsung and Sony Ericsson to release a number of i-mode-compatible handsets. Still, none of these models were developed exclusively for i-mode. The only exclusive i-mode handsets were developed by Japanese manufacturers, which had low brand recognition to European end-users.

In terms of content and applications, KPN continued to expand the number of i-mode sites, totaling around 250 providers before the service would be phased out in 2007. Meanwhile, even though it had put significant amount of resources in i-mode, it still needed to support mobile Internet services based around the WAP protocol, as the large majority of KPN's handsets comprised non-i-mode

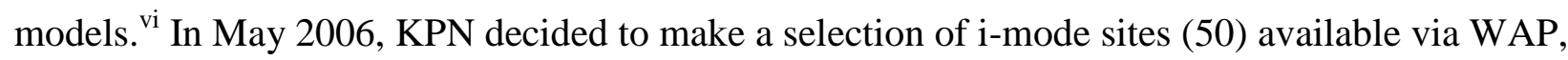
hoping to attract more users to the complete i-mode service. Still, the strategy of selectively disclosing i-mode content would have no significant impact on the success of the service. Finally, in July 2007 KPN announced its decision to phase out the service.

\section{Regulation and Deregulation Processes: Comparison between Japan and the Netherlands}

Regulation plays a crucial role in defining market conditions in mobile telephony, since they allocate the radio spectrum licenses that provide the conduit for transmitting data wirelessly -- as such, regulators can shape the nature of competition (Kushida, 2007). In Japan, the regulatory framework shaped competition to the advantage of the network operator. In particular, it 
strengthened the position of NTT Docomo by weakening outside competition and also increased its bargaining power over local handset makers, who were largely confined to the Japanese market. ${ }^{\text {vii }}$

By contrast, in the Netherlands, the regulatory framework in the Netherlands has resulted in strong competition for incumbent operator KPN. ${ }^{\text {viii }}$ Combined with standardization dynamics, expanded upon in the next section, this has had a strong influence on KPN's (and other GSM operators') capability development.

In 1994, partial privatization of KPN was initiated. The next year a mobile license was granted to challenger Libertel (later acquired by Vodafone). Additional $2 \mathrm{G}$ licenses were made available in 1998, resulting in competition amongst four (initially five) competitors. Though its market share has decreased over time, KPN has always retained its market leader position.

Overall, the Dutch telecommunications market is considered to be one of the most competitive in Europe. For example, in 2007 the European Competitive Telecommunications Association (ECTA), an organization of new entrant telecoms operators, ranked the Netherlands second in terms of competitiveness after the UK. As such, it may be argued that KPN has faced a tougher competitive environment compared to NTT Docomo. For example, in 1999 OPTA further encouraged competition by designating KPN and Libertel as holding significant market power. Further, mobile number portability was introduced in 1999, making it, together with the UK, among the first countries in Europe to do so (Buehler and Haucap, 2004). ${ }^{\text {ix }}$ Furthermore, in contrast to the Japanese "beauty contests", many national regulators in Europe, including the Netherlands, awarded 3G licenses via competitive bidding auctions. As a result, some of these licenses, especially those auctioned at the height of the dotcom bubble, were auctioned at very high costs, putting additional financial pressure on many network operators. ${ }^{\mathrm{x}}$ In the Netherlands too, $3 \mathrm{G}$ license costs were substantial and would initially constitute one third of KPN's total debt (Economist, 2001). 


\section{Standardization Dynamics in Japan and in the Netherlands}

Standardization dynamics followed different paths in Japan and in the Netherlands, with important implications for firms' capabilities and relative bargaining power. In Japan, the lack of global uptake of the Japanese PDC (for Personal Digital Cellular) network standard had important repercussions for both the intensity of competition among operators, and set limits on the expansion of handset makers. By contrast, in Europe, the success of the GSM standard had the reverse effect: the standard intensified competition for incumbent operators, while expanding opportunities for handset makers.

The confinement of the PDC standard to Japan had important repercussions for the Japanese market. In particular, it constituted an advantage for NTT Docomo, since it dissuaded outside competitors from entering the market. Following the liberalization of the handset market, consolidation of network operators led to a situation where thirteen handset makers (only two of which, Nokia and Motorola, were non-Japanese) were supplying three operators (Haas, 2005). The dependency of Japanese handset makers on their local market was further exacerbated by their difficulties to enter more lucrative GSM markets; prohibitive licensing costs for non-IP holders were an initial impediment here (Bekkers, Verspagen and Smits, 2002). Furthermore, attempts to enter foreign markets by cooperating with European i-mode providers were, as mentioned, largely unsuccessful.

In the Netherlands, by contrast, standardization benefited handset and equipment providers more than network operators. In particular, the success of the GSM standard allowed a number of handset and equipment providers (in particular Nokia and Ericsson, prior to that largely confined to their small national markets) to expand, establishing themselves as multinational players (Steinbock, 2003). Spurred by rapid growth and global expansion, their underlying knowledge base and capabilities developed accordingly. A handful of GSM handset makers would come to dominate the 
market, targeting their handsets and equipment to more than 200 network operators in over 100 countries. As such, during the global expansion of GSM in the mid to late 1990s major manufacturers had strong incentives to prevent fragmentation and therefore refused to produce customized handsets (Haas, 2005).

Meanwhile, incumbent network operators such as KPN were primarily engaged in fending off competition, emanating from new entrants as well as incumbent providers expanding abroad. In this process, the technical knowledge and "R\&D engines" of the mobile telecommunications industry had steadily moved from the research laboratories of incumbent operators into the domain of specialized equipment manufacturers (Hommenen \& Manninen, 2003). Focusing on their core capabilities allowed some new entrants (e.g. Vodafone) to expand globally; collectively however, GSM network operators increasingly ceded technological control to the specialized handset and equipment providers. Operators recognized this and responded through individual initiatives such as i-mode and Vodafone Live. In addition, network operators, including KPN, united in the M-services initiative, an attempt to specify a minimum set of requirements to handset makers, recognizing the mutual benefits for all operators. However, this collective initiative also failed to catch on, due to coordination problems among operators, lack of technological competencies and bargaining power (Haas, 2005).

The development of WAP provides another illustration of the difference between Japan and Europe. WAP was part of the first attempt to offer mobile Internet services in GSM markets. These services failed to rouse much interest from application developers and end-users. The approach differed fundamentally from solutions such as i-mode, in that WAP was set up by handset makers to act essentially as a standardized protocol for data delivery. As such, WAP had not been designed to include any of the features of i-mode such as revenue sharing, micro-payments, and initially not even the standard HTML (HyperText Markup Language) language, which would have made a 
difference for application developers. Rather, WAP used WML (Wireless Markup Language), a new markup language that made it more cumbersome for application developers to develop WAP based services (as opposed to i-mode which was based around cHTML (Compact HTML) from the start). In short, the handset makers, who had taken the technological lead in WAP, did not create or protect incentives for complementary developers (such as application developers). European operators, because of their diminished capabilities, largely lacked the capabilities to knowledge to specify handsets requirements, and to set up the billing or micropayment systems which would have incentivize application developers. ${ }^{\mathrm{xi}}$ So, from the perspective of the ecosystem, WAP failed to protect the incentives of all required complementors. In contrast, i-mode, with its reliance on cHTML (an easy language for application programmers) and its revenue-sharing model using the micro-payment method (which allowed application developers to make money easily on their applications) was a more compelling proposition for a wide class of complementors.

\section{Interpretation: Differences in Industry Architecture account for different outcomes when implementing platform leadership strategies}

This section presents our interpretation of the case evidence, with the view to explain the puzzle mentioned at the outset of the article (success of i-mode in Japan, failure in the Netherlands). We interpret the differences in context (in particular different outcomes of the deregulation process as well as the emergence in Europe of dominant handset makers associated with the GSM standard) as leading to differences in industry architectures with, in particular, in European operators' diminished capabilities and bargaining power over handset makers. These, in turn strongly affected the chances of success of operators such as KPN, despite its attempt to replicate in its geography what had been a successful strategy in Japan. 


\section{Firms' scope, relationships, capabilities and bargaining power}

Differences between Japan and Europe in regulation and standardization led to a different set of firms' scope, knowledge base and capabilities, relationships, and ultimately bargaining power vis-àvis other firms. The Japanese roll-out of i-mode suggests that NTT Docomo possessed, or could successfully acquire, the relevant knowledge and capabilities to successfully coordinate the service. These include building the necessary billing and micropayment systems, setting up revenue sharing arrangements and providing various network adjustments. As such, the platform successfully incentivized content providers and handset makers. Most importantly, NTT Docomo had the ability to specify handset requirements to ensure seamless integration between the handset and the service. By contrast, no European network operator possessed comparable knowledge or capabilities at the time NTT Docomo introduced i-mode: as mentioned, European mobile Internet services were initially based on WAP, a network protocol where handset providers, not network providers, took the lead (Sigurdsson, 2001).

Tables 2 and 3 describe the key actors and the roles they fulfill. The structure of relationships is visually illustrated in Figures 2 and 3.

[Insert Table 2 and 3, Figures 3 and 3 about here]

For i-mode to provide an architectural advantage or a "bottleneneck" for KPN (in other words, for KPN to achieve platform leadership with i-mode), KPN would have needed to successfully induce both competition and innovation at the level of complementary products (such as handsets and applications). It failed on both accounts. It was not able to provide the right incentives to handsets makers to create i-mode specific handsets (complementarity). And it was not able to muster a compelling enough business model that would incentivize its complementors (handset makers and application developers). 
Fransman's (2002) account of the mobile industry provides further explanation of the observed differences in knowledge and capabilities, analyzing how European network providers have increasingly become reliant on specialist equipment providers more actively engaged in $R \& D$. In fact, European operators have an R\&D intensity comparable to sectors typically not considered to be high-tech, e.g. beverages and personal care (Fransman, 2002). Crucially, NTT Docomo provides the key exception here. Specifically, in 1999, the year both i-mode and WAP were introduced, the R\&D expenses as a percentage of sales of NTT (NTT Docomo's parent company) are approximately twice as large as its main competitors (AT\&T, BT, Deutsche Telekom and France Telecom), and the R\&D expenses per employee are approximately five times as large (Fransman, 2002)

It is important to be precise about the role of R\&D. While NTT Docomo's strong commitment to R\&D has often been remarked (see e.g. ITU 2002), and should not be underestimated, we should also note that NTT Docomo's main competitors, KDDI and Softbank, also have the relevant orchestrating capabilities - despite lacking the size of NTT Docomo's R\&D budget. ${ }^{\text {xii }}$ As such, we interpret the distribution of $\mathrm{R} \& \mathrm{D}$ expenses in this context as follows: on the one hand, it provides an indication of the rise of handset vendors in Europe. On the other hand, in the Japanese case, it also illustrates the importance of maintaining these capabilities. However, given the relatively high R\&D expenses of globally dominant operator Vodafone, R\&D expenses by themselves appear not to be a sufficient explanation. The regulatory framework and standardization, expanded upon earlier, have also played an important role. As such, simply increasing R\&D expenses would probably not restore the operator's position in Europe, given the way the industry architecture has emerged as a path-dependent, historically shaped process. Therefore, overall, it is the historically developed structure of the relationships that is key here and NTT Docomo's initial capabilities may have been a prerequisite to establish the current Japanese industry architecture. 
In Japan, these capability differences are subsequently reflected in the type of actor that provides the main brand to the end-user. NTT Docomo's informal agreements to delay handset shipments (Funk, 2003) was particularly harmful to competing operators, though it also impacted on handset makers. There were incentives for handset makers to cooperate with these exclusivity arrangements: it gave them access to information ahead of their rivals; it reduced competitive pressure as only a small number of manufacturers could join the arrangement; and it guaranteed sales volume as the operator committed itself to purchase a first batch of models (Haas 2005). At the same time, it made it more difficult for handset makers to establish their brand to consumers. As a result, in Japan the "guarantor of quality" (Jacobides et al., 2006) function is taken up by the network operator. In Japan, i-mode has enabled NTT Docomo to further strengthen its position in the industry architecture: it has enhanced its brand, and expanded its scope to payment services, music downloads and mobile television. By contrast, when European operators decided to introduce imode - effectively an attempt to reshape the industry architecture - they were too late. In Europe, handset makers had firmly established themselves as "guarantors of quality" (ITU, 2002) and also possessed the relevant capabilities to consolidate and expand this role, in particular market leader Nokia. ${ }^{\text {xiii }}$ Efforts of European operators to counter this can be witnessed in attempts to either cobrand handsets or reduce the visibility of the handset maker altogether in the case of handsets by ODM suppliers. ${ }^{\text {xiv }}$ Yet, handset makers, especially top tier vendors, also realized it was not in their interest to diminish their brand by allowing another actor (the operator) to co-brand.

\section{Japan and the Netherlands: Different Industry Architectures}

For historical reasons that relate to regulation and standardization processes, the European and Japanese contexts differed in several respects. As a result, the respective industries differed not only in which firm(s) were the main sources of innovation (i.e., who created value) in the industry, but also how value was captured and appropriated in the industry (i.e., who held bargaining power over 
other actors in the ecosystem - or network of co-specialized assets). Both the capacity to create value and the ability to hold bargaining power were underpinned by specific firms' capabilities, as we explained earlier in this section. While in Japan the incumbent operator was both the repository of capabilities and the holder of bargaining power over the other actors of the ecosystem, in the Netherlands the operator held neither. In Japan, bargaining power as well as innovation lay with the operator NTT Docomo. The enduring and embedded structure of relationships between economic players, combined with the firms' distinct respective abilities to create value by innovation as well as to appropriate value due to their bargaining power, constrained the network operators' ability to achieve similar outcomes from replicating the platform strategy that worked in Japan.

Taken together, these variables (firm's scope, bargaining power, capabilities, and relationships with other firms), correspond well to what Jacobides et al. (2006) refer to as industry architectures. Let us recall that in their definition, industry architectures are the templates that define the nature of cospecialization, as well as the way surplus is divided between the co-specialized players. More precisely, they provide two templates, each comprising a set of rules: 1) a template defining the division of labour, i.e. who can do what, and 2) a template defining the division of surplus, or revenue, i.e. who gets what.

In our setting, a more accurate description of the challenge that KPN faced with i-mode is that, in contrast to Japan where i-mode was the first platform in mobile telephony, in GSM markets there was already an incumbent industry platform with its own ecosystem, -- and that platform was constituted by GSM-compatible handsets from players such as Nokia. That platform existed, albeit in a different layer of the industry architecture than the layer where the operators were competing. It is possible (and a fascinating area of research ahead) that, as both NTT Docomo and KPN were operators as opposed to handset makers, they both did not quite anticipate the contrarian effect on their plans coming from the ranks of handset makers. With the benefit of hindsight, it is quite easy 
to see how dominant handset makers would have no interest in facilitating i-mode's success in Europe. Handset makers like Nokia not only held bargaining power vis-à-vis operators, but also visà-vis application developers, and vis-à-vis end-users (with their strong brand, fuelled by significant investment in advertising). In fact, dominant handset makers already acted as platform leaders, and, as Gawer and Cusumano (2008) point out, this means that they were benefiting from lots of competition between poorly differentiated complementors (which included operators). Therefore, it was in the interest of European handset makers to keep operators' offering as undifferentiated as possible, and in this regard, operator driven i-mode was presenting a threat to their continued superior bargaining power. I-mode, an innovative offering coming from the ranks of operators, did not appear as a winning proposition to handset makers - and, as the handset makers had greater bargaining power in Europe, used it to prevent i-mode from succeeding.

Further, the lack of compelling content played a role in i-mode failure, as it led to an inferior offering, and a poor value proposition for the end-user. While "lack of content" is part of what the platforms literature would already warn us to pay attention to as an explanation for success or failure, we still believe that to uncover the reasons why KPN failed to stimulate content, it is useful to look at the situation from an industry architecture perspective. The reasons behind the lack of compelling content are well explained by an analysis of the industry architecture, such as the European operators' diminished scope, and capabilities (when compared to NTT Docomo) and their relationships with developers.

KPN, with its restricted scope and capabilities, was not in a position to usefully influence the specifications of mobile standards such as WAP, which specified essential programming tools for application developers to create mobile applications. Operators like KPN also lacked the bargaining power to convince most application developers to create i-mode specific content, as in Europe developers expected to create applications that would not be operator-specific. In the European 
context, where handset makers were the dominant players (over and above network operators), developers had come to expect that applications would work on any network. As a consequence, it was usually not in their interest to develop for an operator specific service, as this would imply they would have to redevelop their applications for other networks. To application developers, investing in operator specific services was to invest in a co-specialized asset with one telecom operator only, with unconvincing appeal to a large user base. Further, as operators had not introduced technical features such as micro-payment capabilities and a billing system, developers lacked business incentives to create and innovate on a stream of compelling i-mode applications.

\section{Alternative explanations}

Let us consider alternative explanations that might explain differences in the outcome of i-mode's commercialization. One explanation, put forward ever since the first success of i-mode became clear, emphasizes cultural differences between Japan and other countries (see e.g. Barnes and Huff, 2003; Ishii, 2004). Specifically, it is suggested that, compared to Europe, Japan might be more disposed towards "electronic gadgets". While this might be true for specific examples, we would suggest that this does not apply to the case of mobile Internet services. In particular, more recent trends such as the strong growth of smartphones (e.g. Apple's iPhone) and other mobile Internet initiatives (e.g. RIM's BlackBerry line of wireless email solutions) appear to point to a latent demand for mobile Internet services in markets outside of Japan (FT, 2009). As such, we think these recent developments illustrate that the specific form through which mobile Internet services are offered is key - and may need to be adjusted to the local industry conditions.

Another explanation that has been suggested is Japan's low fixed Internet penetration at the time of introduction of i-mode. While Japan's initial Internet penetration may indeed have been lower than other advanced economies, the premise underlying this explanation does not seem to hold. Namely, this explanation appears to assume that fixed and mobile Internet services are substitutes; instead, 
empirical data suggests that they are largely complementary. For example, in Japan demand for broadband Internet has been very high (currently one of the leading countries in broadband penetration), and has not come at the expense of mobile Internet usage (Henten et al. 2004; ITU, 2003). Of course, given the nature of the data we cannot fully rule out alternative explanations. However, recent developments in both Japan and Europe appear to counter explanations that have focused on cultural or infrastructural differences to explain differences in i-mode commercialization outcomes.

In conclusion, in Japan, NTT Docomo had the market influence and systems knowledge to orchestrate an extensive ecosystem around its i-mode service. However, a combination of deep historical differences in standards, regulation and market structure reduced the bargaining power of European operators and their subsequent ability to act as platform leader. As a result, while in Japan the industry architecture was shaped by NTT Docomo's successful platform establishment, platform leadership itself was circumscribed and bounded by the European industry architecture.

\section{Discussion and Conclusion}

Our study's main finding is that the underlying industry architecture prevented a firm (KPN) to successfully achieve platform leadership, despite the fact that it was replicating a successful platform strategy in a different geographical context, all the while benefiting from the support of the very firm (NTT Docomo) that had been spectacularly successful in the original context. Attempts to apply similar platform strategies in two different contexts, -- characterized by two distinct industry architectures--, led to radically different outcomes: success on the one hand, failure on the other. Our study therefore suggests that underlying industry architectures, if not properly taken into account, can thwart the effect of what appears to be well-formulated strategies. We therefore suggest that the industry architecture concept can be usefully combined with platform theories. 
As a corollary to our main finding, our analysis also suggests that platforms and industry architectures may require a "fit". The European operator did not match the roles of its Japanese equivalent, in particular in terms of vertical scope and resulting differences in bargaining power. This clearly negatively affected deployment of the platform in Europe. Therefore, this case suggests that the deployment of a platform to a different type of industry architecture may prove elusive, or that the platform may need to be adapted in such a way that a better fit with the existing architecture is reached. This observation falls in line with existing research on the co-evolution between the existing distribution of capabilities and transaction costs (see Jacobides and Winter, 2005). They also underline the importance of taking into account a firm's “design capabilities" (Gawer 2009), i.e. whether or not actors should fulfill the role of systems integrator or component supplier.

Overall, our study extends and confirms existing research on industry architectures and platforms. In particular, platforms and industry architectures appear to provide complementary perspectives. The paper contributes to the literature on industry architecture by unpacking interactions between evolutionary processes, industry architecture, and business strategies. It also contributes to the platforms literature, by positing that firms' ability to successfully pursue platform strategies depends on industry architecture. The case suggests that differences in roles across industry architectures affect the likelihood for platform strategies to be successfully implemented. Further, we have seen how different knowledge bases, in part a function of regulatory frameworks and standardization dynamics, might shape these roles.

We suggest therefore that theories of industry architecture are useful to refine and complement platform theories. Part of a tradition of theories of strategy, platform theories (which are still in their early days) have tended to focus on "action", on the strategic moves that managers should do to transform their product into a platform. This paper suggests that these theories may not have paid 
enough attention to the structural reasons why these strategic moves are not always possible. This paper makes the case for paying careful attention to industry architecture as potentially limiting the scope for action in some areas. A finer understanding of industry architecture, combined with recent findings from platform research should allow more accurate strategic recommendations.

Focusing on actors and differences in their roles can help us understand why platforms might show differences in regional take-up. From a technological perspective it is indeed true for both regions that handset makers provide handsets and network operators provide network service. However, when we focus on the subsequent definition of that role, interesting distinctions and tensions come to light. Yes, handset makers provide handsets, but (in Europe) they increasingly also provide services that traditionally would be beyond their boundaries. Likewise, network operators, in Japan as well as Europe, attempt to shape their boundaries to increase control and value appropriation.

In Japan, the local set of regulations mostly favored the incumbent network operator vis-à-vis handset providers as well as competing network operators. Here, network operators, in particular the incumbent, were able to maintain their knowledge base and preserve control over branding and overall development of the system. By contrast, the European regulatory framework increased competition for incumbent network operators, and in the wider context of GSM standardization allowed handset and equipment providers to expand their business globally, enhancing their capabilities in that process. As a result, European operators relinquished technological control to specialist handset and equipment providers. In that process, some of these were able to capture a significant part of the value by becoming the guarantor of quality, manifested for example in branding and marketing towards end-users.

That said, given the exploratory nature of this study and the limited setting that compares only two firms in two geographies, we would suggest that our finding should be taken as preliminary. It 
would be worthwhile to investigate this further, treating our finding as a proposition and designing further studies aimed at testing it rigorously, by using a combination of supplementary case studies in different industries, and eventually through the means of a deductive study, using data obtained from a larger sample.

\section{Limitations and directions for future research}

This study knows several limitations, pointing to ways in which our results might be extended in future work. First, the lack of successful foreign expansion of Japanese telecoms firms (both operators and handset makers) appears to reaffirm what has been referred to as the "paradox of Japanese info-communication companies" (Fransman, 1995, 1999). Though both Japanese mobile network operators and handset makers are at the forefront technologically, they have mostly been unable to replicate this success in other regions - in sharp contrast to other industries such as automobiles and consumer electronics. As such, it emphasizes the importance of the institutional structure of value chains in international expansion, confirming the observation that differences herein can be most pronounced in service-based industries, given the greater room for difference in terms of structuring the industry architecture (Jacobides, 2008; Jacobides and Kudina, 2009). The problem of architectural change also appears to be related to the broader concept of business models (Amit and Zott, 2001; Chesbrough and Rosenbloom, 2002; Ballon, 2009). As mentioned by Ferraro and Gurses (2009), innovation in business models might constitute a necessary, though not sufficient condition for establishing shifts in industry architecture. This study has not focused on these issues, which may constitute a fruitful area for further research.

A second fruitful area for further research could attempt to analyze whether and to which extent industry architecture could be strategically manipulated. This paper has proposed that industry architectures, when not properly taken into account in the formulation of business strategies, can prevent strategies' successful implementation and limit the effect of deliberate managerial action. 
Our paper therefore takes largely the view that industry architectures are structures that are hard to manipulate. However, Jacobides et al. (2006) also suggest that, although structural, industry architectures can be manipulated by industry actors. To some extent, NTT Docomo did this in Japan, and a straightforward interpretation of platform leadership strategies is to construe them as an attempt to create "architectural advantage" (as has been noted by Jacobides et al., 2006). We find particularly intriguing the hypothesis from Jacobides et al. (2006) that posits that assets "complementarity" and "mobility" determines the extent to which actors can shape industry architecture. Recent empirical papers such as Ferraro and Gurses (2009) provide evidence of how players in the US motion picture industry successfully shaped the industry architecture.

At the same time though, our paper highlights the effect of regulation, as well as the process of standardization on the development of firms' capabilities and bargaining power over other actors which can in turn affect firms' ability to create but also to appropriate value. As such, we should indicate that the study also highlights the unpredictable nature of these processes, and therefore, the difficulty for firms to manipulate them to achieve strategic advantage. In the context of our case study, several actions that were taken had consequences that were probably not foreseen. For example, it is quite likely that the cumulative impact of a combination of a historically strong PTT in terms of R\&D capabilities (NTT), a network standard that would remain localized to Japan, consolidation among network operators, and liberalization of the equipment market, were not foreseen by the various actors involved. Equally, it is unlikely that the impact of various measures in Europe, in particular the global success of the GSM network standard, de-regulation of infrastructure, and considerable financial strains due to disproportionately high licensing costs, were anticipated. This unpredictability suggests the need for firms to be cautious about their own expectations about how much they can shape the industry context (including the industry architecture) in which they operate. On the one hand, individual actors obviously have the ability to influence specific lines of action, including e.g. the properties of standards. Likewise, through 
lobbying firms may also shape the regulatory framework in ways that advance their individual or collective interests. On the other hand, our case also suggest that the cumulative result of individual decisions, which may lead to unpredictable results due to interactions between individual actions, are beyond the immediate influence of even the most farsighted actors.

In addition, our study has focused on a "macro" level of analysis; as such we have largely ignored the design process of the various artefacts that make up the system, for example particular network or interface standards. A micro-level analysis of such a design process of such a standard could shed more light on the various strategic trade-offs involved in this process. For example, Camuffo and Zirpoli (2009) shed more light on such a design process in their comparative study of a subsystem in the automobile industry. Importantly, they highlight the pragmatic and often political approach surrounding the way the division of labor is shaped. In our context it would also be of interest to investigate the repercussions of particular design choices, e.g. characteristics of the standards subsumed in the i-mode platform or the design choices of particular network or messaging standards.

Finally, in terms of empirical scope, i-mode constitutes only one of several platforms operating in the mobile industry; there are platforms directly competing (e.g. Vodafone Live) as well as ones located at different parts of the value chain (e.g. the Symbian operating system). Therefore, we focused on only one platform that is part of a wider competitive landscape. Future work taking a broader scope may be able to focus on dynamics between platforms at different levels, in an attempt to understand competitive dynamics at the overall industry level. ${ }^{\mathrm{xv}}$ Such an analysis would be particularly worthwhile for this industry, given the key role of bottlenecks - or, using telecoms industry parlance, "control points" - in the migration of control and value. For example, in the mobile industry, platforms at the level of the operating system are increasingly being commoditized (cf. recent initiatives by Google and Nokia to provide royalty free platforms based on open source 
licensing). This makes it difficult for actors that might wish to establish a bottleneck at this level (e.g. Microsoft). Likewise, industry actors appear to be increasingly cognizant of the way value might be appropriated at different parts of the value chain. This is reflected for example in music download initiatives by Apple and Nokia that bypass the infrastructure of the network operator. In turn, network operators try to maintain control not only through services like i-mode, but also by offering competing music platforms and, in Japan, broadening their portfolio to a range of other services such as mobile payments; highlighting an increasing tendency for firms to integrate downstream into services (Davies, 2004; Chesbrough \& Davies, 2009).Given the state of flux the industry is currently in, such an analysis would certainly be challenging. Nevertheless, it seems likely that work in this area could achieve much to further our understanding of how changes in the nature of bottlenecks provide a reflection of the way value migrates across different parts of the value chain. 
Table 1: deployment of $\mathrm{i}$-mode in Japan and various European countries

\begin{tabular}{|c|c|c|c|c|c|}
\hline Country & Operator & $\begin{array}{l}\text { I-mode } \\
\text { introduction }\end{array}$ & $\begin{array}{l}\text { I-mode subscribers } \\
\text { millions - (total } \\
\text { subs) - i-mode users } \\
\%^{*}\end{array}$ & Current status & Handsets \\
\hline Japan & $\begin{array}{l}\text { NTT } \\
\text { Docomo }\end{array}$ & Feb 99 & $48(54)-89 \%$ & Active & $\begin{array}{l}\text { Casio, Fujitsu, Hitachi, Kyocera, } \\
\text { Mitsubishi, NEC, Panasonic, Sanyo, } \\
\text { Sharp, SonyEricsson, Toshiba; HTC, LG, } \\
\text { Motorola, Nokia, Pantech/ Curitel, RIM, } \\
\text { Samsung }\end{array}$ \\
\hline Germany & E-Plus & Mar 02 & $1.1(7.8)-14 \%$ & $\begin{array}{l}\text { Phased out Apr } \\
08\end{array}$ & $\begin{array}{l}\text { NEC, Toshiba, Panasonic, Mitsubishi, } \\
\text { Samsung }\end{array}$ \\
\hline Netherlands & KPN & Apr 02 & $0.8(4.9)-16 \%$ & $\begin{array}{l}\text { Phased out Jul } \\
07\end{array}$ & $\begin{array}{l}\text { NEC, Toshiba, Panasonic, Mitsubishi, } \\
\text { Samsung }\end{array}$ \\
\hline Belgium & BASE & Oct 02 & $0.3(1.4)-21 \%$ & $\begin{array}{l}\text { Handset } \\
\text { procurement } \\
\text { cancelled }\end{array}$ & $\begin{array}{l}\text { NEC, Toshiba, Panasonic, Mitsubishi, } \\
\text { Samsung }\end{array}$ \\
\hline France & Bouygues & Nov 02 & $1.1(7.2)-15 \%$ & $\begin{array}{l}\text { Handset } \\
\text { procurement } \\
\text { cancelled }\end{array}$ & NEC, Toshiba \\
\hline Spain & Telefonica & Jun 03 & $1.1(19)-6 \%$ & $\begin{array}{l}\text { Handset } \\
\text { procurement } \\
\text { cancelled }\end{array}$ & NEC \\
\hline Italy & Wind & Nov 03 & $0.7(14)-5 \%$ & $\begin{array}{l}\text { Handset } \\
\text { procurement } \\
\text { cancelled }\end{array}$ & NEC \\
\hline Greece & Cosmote & Jun 04 & $0.5(4.2)-12 \%$ & $\begin{array}{l}\text { Handset } \\
\text { procurement } \\
\text { cancelled }\end{array}$ & NEC, Panasonic \\
\hline Russia & MTS & Sep 05 & $0.1(48)-0.2 \%$ & $\begin{array}{l}\text { Phased out Jul } \\
06\end{array}$ & NEC \\
\hline UK & $\mathrm{O} 2$ & Oct 05 & $0.25(14.2)-2 \%$ & $\begin{array}{l}\text { Phase out } \\
\text { planned Mid } 09\end{array}$ & NEC, Samsung \\
\hline Ireland & $\mathrm{O} 2$ & Oct 05 & n/a (1.5) & $\begin{array}{l}\text { Phase out } \\
\text { planned Mid 09 }\end{array}$ & NEC, Samsung \\
\hline Bulgaria & Globul & Sep 06 & $\mathrm{n} / \mathrm{a}(1.3)$ & Active & Samsung, Motorola \\
\hline Romania & Cosmote & May 07 & $\mathrm{n} / \mathrm{a}(2.0)$ & Active & Sony Ericsson, Samsung, LG, Sagem \\
\hline Germany & $\mathrm{O} 2$ & $\begin{array}{l}\text { Introduction } \\
\text { cancelled } \\
\text { (Mar06) }\end{array}$ & & & \\
\hline
\end{tabular}


Table 2: Actors and roles in the Japanese mobile industry

\begin{tabular}{|l|l|l|}
\hline \multirow{2}{*}{ Actor } & Roles \\
\cline { 2 - 3 } $\begin{array}{l}\text { (1) Infrastructure } \\
\text { equipment provider }\end{array}$ & $\begin{array}{l}\text { Develop network infrastructure } \\
\text { equipment } \\
\text { (base stations, switches etc) }\end{array}$ & $\begin{array}{l}\text { Supplier to all network operators, adapted to network } \\
\text { standard (PDC-WCDMA or CDMA/CDMA2000) }\end{array}$ \\
\hline $\begin{array}{l}\text { (2) Mobile handset } \\
\text { provider }\end{array}$ & $\begin{array}{l}\text { Develop handset, customized to } \\
\text { network operators' requirements }\end{array}$ & $\begin{array}{l}\text { Supplier to all network operators, adapted to network } \\
\text { standard (PDC-WCDMA or CDMA/CDMA2000); } \\
\text { operators require exclusivity }\end{array}$ \\
\hline (3) Network operator & $\begin{array}{l}\text { Provide network service } \\
\text { Specify functionality and brand } \\
\text { handset } \\
\text { Manage voice and data (inc third } \\
\text { party content) billing }\end{array}$ & $\begin{array}{l}\text { Buyer from handset providers, requires exclusivity } \\
\text { Supplies to all independent retailers } \\
\text { Regulates content and applications provider }\end{array}$ \\
\hline (4) Content provider & $\begin{array}{l}\text { Create content (e.g. news, } \\
\text { entertainment info) and } \\
\text { applications (e.g. games) }\end{array}$ & $\begin{array}{l}\text { Supplier to network operator via proprietary network } \\
\text { service }\end{array}$ \\
\hline $\begin{array}{l}\text { (5) Independent } \\
\text { retailer }\end{array}$ & $\begin{array}{l}\text { Sell handsets } \\
\text { Sell network subscriptions }\end{array}$ & $\begin{array}{l}\text { Buyer of handsets and network subscriptions from all } \\
\text { network operators } \\
\text { Supplier of handsets and network subscriptions to end- } \\
\text { users }\end{array}$ \\
\hline (6) End-user & $\begin{array}{l}\text { Buys handsets and network service from independent } \\
\text { retailers }\end{array}$ \\
\hline
\end{tabular}

Table 3: Actors and roles in the European-Netherlands mobile industry

\begin{tabular}{|c|c|c|}
\hline \multirow[t]{2}{*}{ Actor } & \multicolumn{2}{|l|}{ Roles } \\
\hline & Scope & Relationships to other actors \\
\hline $\begin{array}{l}\text { (1) Infrastructure } \\
\text { equipment provider }\end{array}$ & $\begin{array}{l}\text { Develop network infrastructure } \\
\text { equipment } \\
\text { (base stations, switches etc) }\end{array}$ & $\begin{array}{l}\text { Supplier to all network operators using GSM } \\
\text { standard }\end{array}$ \\
\hline $\begin{array}{l}\text { (2) Mobile handset } \\
\text { provider }\end{array}$ & $\begin{array}{l}\text { Specify handset features and design } \\
\text { Brand handset } \\
\text { Sell handset }\end{array}$ & $\begin{array}{l}\text { Supplier to all network operators*, retailers, or } \\
\text { end-users }\end{array}$ \\
\hline (3) Network operator & $\begin{array}{l}\text { Procure handsets } \\
\text { Provide network service } \\
\text { Manage voice and data billing } \\
\text { Sell network service and handset }\end{array}$ & $\begin{array}{l}\text { Buyer from all handset providers. } \\
\text { Supplier to all independent retailers, or directly } \\
\text { to end-users }\end{array}$ \\
\hline (4) Content provider & $\begin{array}{l}\text { Create content (e.g. news, } \\
\text { entertainment info) and applications } \\
\text { (e.g. games) }\end{array}$ & $\begin{array}{l}\text { Supplier of content and applications directly to } \\
\text { end-user via standard protocol (e.g. WAP, SMS) }\end{array}$ \\
\hline $\begin{array}{l}\text { (5) Independent } \\
\text { retailer }\end{array}$ & $\begin{array}{l}\text { Sell handsets } \\
\text { Sell network services }\end{array}$ & $\begin{array}{l}\text { Buyer from all handset makers and all network } \\
\text { operators } \\
\text { Supplier to all end-users }\end{array}$ \\
\hline (6) End-user & Purchase handset and mobile service & $\begin{array}{l}\text { Buyer from all handset makers and network } \\
\text { operators. } \\
\text { Can mix and match network and handset type } \\
\text { via independent retailer* }\end{array}$ \\
\hline
\end{tabular}

\footnotetext{
* Exceptions are (1) mobile phones (typically low-end) exclusively procured from "ODM" handset makers and branded by the network operator, and (2) "premium" handsets such as the Apple iPhone which in some countries are supplied exclusively; however, in the second case, this form of exclusive tying is not allowed in some countries because of the regulatory framework.
} 
Figure 1: Platform - Industry architecture interaction framework

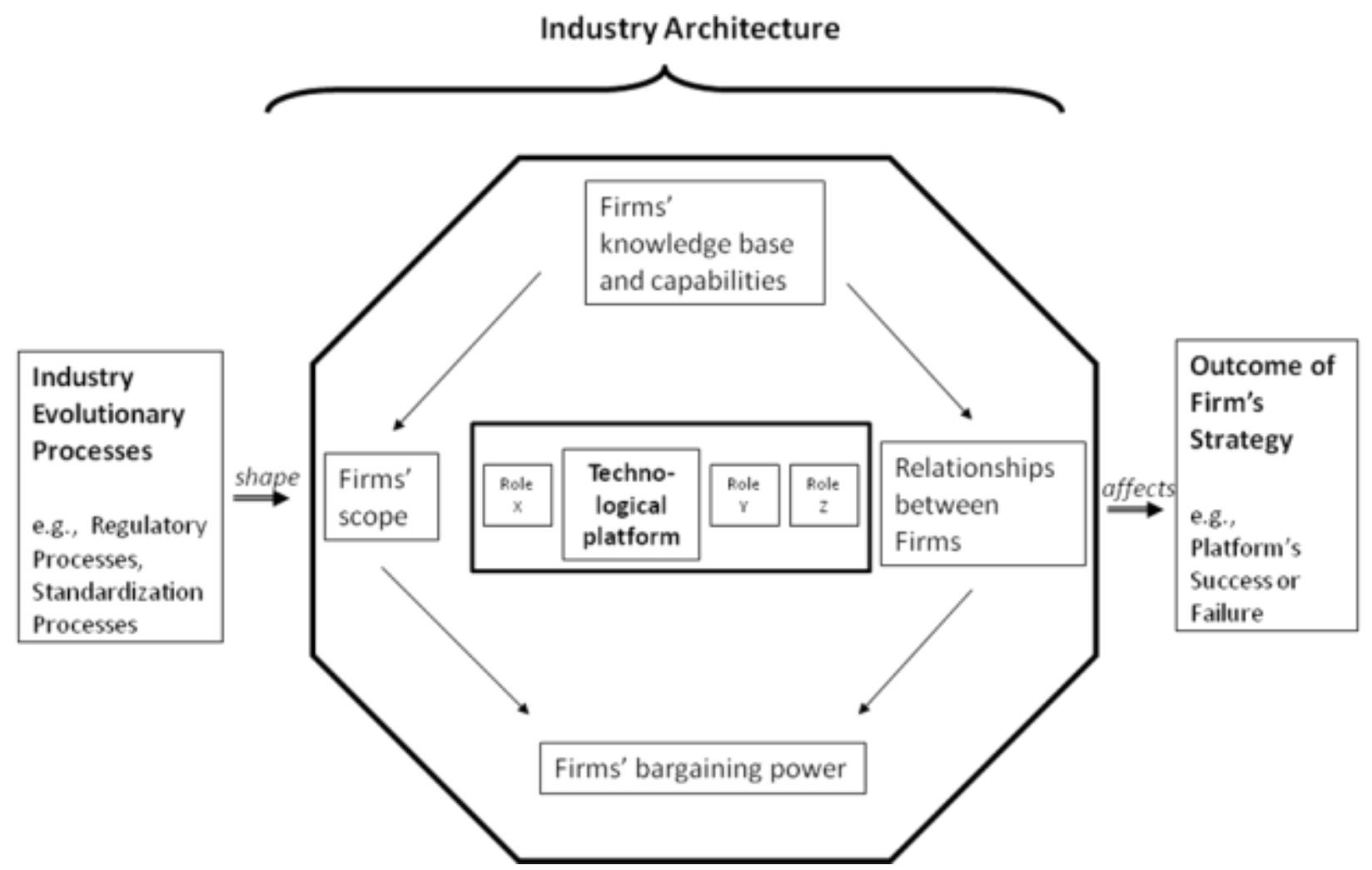

Figure 2: Relationship structure mobile industry in Japan

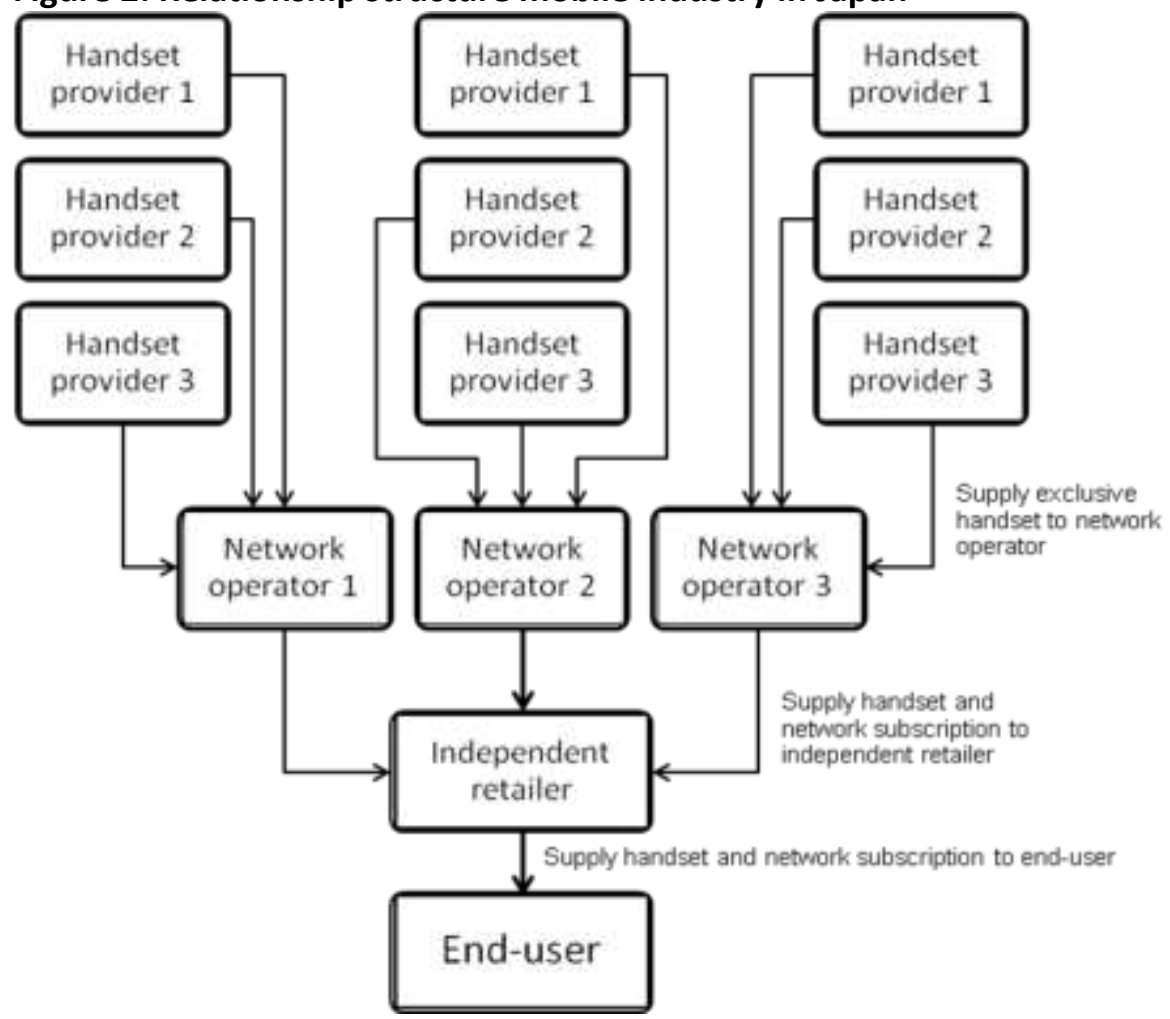


Figure 3: Relationship structure mobile industry in the Netherlands

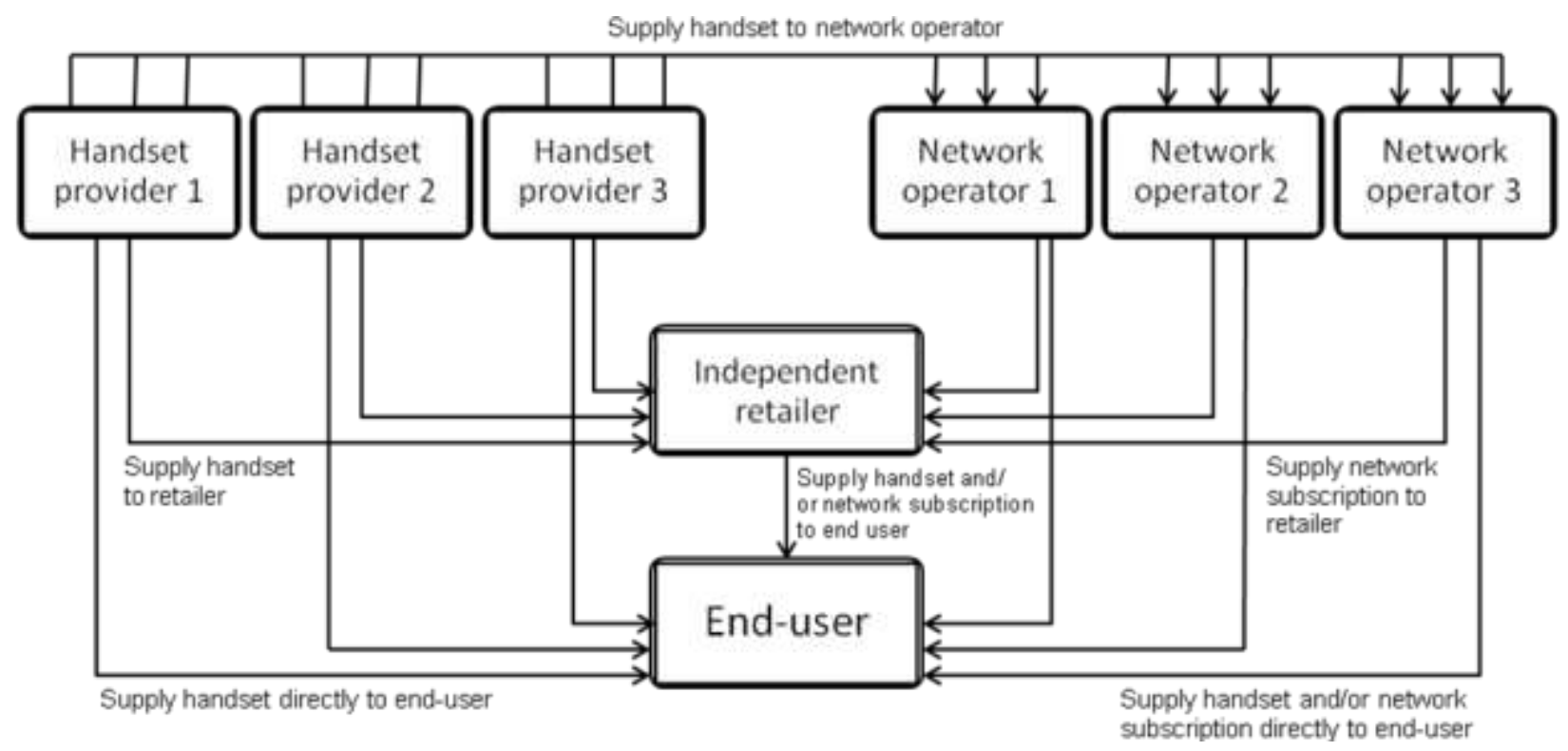




\section{References}

Amit, R and C. Zott, 2001, 'Value creation in e-business'. Strategic Management Journal, 22: (67): 493-520.

Baldwin, C.Y. and K.B. Clark, 2000, Design Rules: The Power of Modularity. Cambridge, MA, US: MIT Press.

Baldwin, C.Y. and C.J. Woodard, 2009, 'The Architecture of Platforms: A Unified View'. In Gawer, A. ed., Platforms, Markets and Innovation, Cheltenham, UK and Northampton, MA, US: Edward Elgar.

Ballon, P., 2009, Control and Value in Mobile Communications: A political economy of the reconfiguration of business models in the European mobile industry. Unpublished doctoral dissertation, Vrije Universiteit Brussel.

Barnes, S.J. and S.L. Huff, 2003, 'Rising sun: imode and the wireless internet'. Communications of the ACM, 46 (11): 79-84.

Bekkers, R., Verspagen, B. and J.Smits, 2002, 'Intellectual property rights and standardization: The case of GSM'. Telecommunications Policy 26: 171-188.

Binmore, K. and P. Klemperer, 2002, 'The Biggest Auction Ever: The Sale of the British 3G Telecom Licenses'. Economic Journal, 112: 74 - 96.

Boudreau, K., 2005, 'The boundaries of the platform: Vertical integration and economic incentives in mobile computing'. MIT Sloan Research Paper.

Brandenburger, A. and B.J. Nalebuff, 1996, Co-opetition, New York: DoubleDay.

Buehler, S. and J. Haucap, 2004. 'Mobile Number Portability'. Journal of Industry, Competition and Trade, 43 (9): 223-238.

Cacciatori, E. and M. G. Jacobides, 2005, 'The dynamic limits of specialization: vertical integration reconsidered'. Organization Studies, 26: 1851-1883.

Camuffo and F. Zirpoli, 2009, 'Product architecture, inter-firm vertical coordination and knowledge partitioning in the auto industry', European Management Review

Chesbrough, H. and A. Davies, 2009, 'Advancing Services Innovation: Five Key Concepts'. In Spohrer, P. Maglio and C. Kieliszewski, eds. Service Science Handbook, New York: Springer.

Chesbrough, H. and R.S. Rosenbloom, 2002, 'The role of the business model in capturing value from innovation: evidence from Xerox Corporation's technology spin-off companies'. Industrial and Corporate Change, 11(3): 529-555.

Cusumano, M.A. and A. Gawer, 2002, 'The elements of platform leadership'. MIT Sloan Management Review, 43: 3. 
Cowhey, P., J. Aronson and J. Richard, 2008, 'Shaping the Architecture of the U.S. Information and Communication Technology Architecture: A Political Economic Analysis'. Review of Policy Research, 26 (1-2): 105-125.

Davies, A., 2004, 'Moving base into high-value integrated solutions: a value stream approach', Industrial and Corporate Change, 13:727 - 756.

Economist, 2001, 'Pass the painkillers', The Economist, May 5, 2001: 71-72.

Eisenhardt, K., 1989, 'Building Theories from Case Study Research'. Academy of Management Review, 14: 532-540.

Eisenmann, T., G. Parker and M. Van Alstyne , 2006, 'Strategies for two-sided markets', Harvard Business Review, 84: 92-101.

Ferraro, F. and K. Gurses, 2009, 'Building Architectural Advantage in the US Motion Picture Industry: Lew Wasserman and the Music Corporation of America'. European Management Review.

Fransman, M., 1995, Japan's Computer and Communications Industry: The Evolution of Industrial Giants and Global Competitiveness, Oxford: Oxford University Press.

Fransman, M., 1999, Visions of innovation: the firm and Japan. Oxford: Oxford University Press.

Fransman, M., 2002, Telecoms in the Internet Age: From Boom to Bust to..? Oxford: Oxford University Press.

FT, 2009. 'As Smartphones Proliferate, Will One Company Emerge as the Clear Market Winner?'. Financial Times, July 1, 2009.

Funk, J.L., 2001, The Mobile Internet: How Japan Dialed Up and the West Disconnected. ISI Publications.

Funk, J.L., 2003, 'Standards, Dominant Designs and Preferential Acquisition of Complementary Assets through Slight Information Advantages'. Research Policy, 32: 1325-1341.

Gawer, A. ,2009a, 'Platforms, Markets and Innovation: An Introduction'. In Gawer, A. ed., Platforms, Markets and Innovation, Cheltenham, UK and Northampton, MA, US: Edward Elgar

Gawer, A. ,2009b, 'Platform Dynamics and Strategies: From Products to Services'. In Gawer, A. ed., Platforms, Markets and Innovation, Cheltenham, UK and Northampton, MA, US: Edward Elgar.

Gawer, A. and M.A. Cusumano, 2002, Platform Leadership: How Intel, Microsoft, and Cisco Drive Industry Innovation, Boston, MA, US: Harvard Business School Press.

Gawer, A. and M.A. Cusumano, 2008, 'How companies become platform leaders'. MIT Sloan Management Review, 49: 28-35.

Haas, M. 2005. Management of Innovation in Network Industries: A Case Study of the Mobile Internet in Japan and Europe. Unpublished doctoral dissertation, Ludwig-Maximilians-Universität München. 
Henten, A, H. Olesen, D. Saugstrup and S.E. Tan, 2004, 'Mobile communications: Europe, Japan and South Korea in a comparative perspective'. INFO, 6: 197-207.

Hommenen, L. and E. Manninen, 2003, 'The Global System for Mobile Telecommunications GSM: Second Generation'. In C. Edquist, ed., The Internet and Mobile Telecommunications System of Innovation: Developments in Equipment, Access, and Content, Cheltenham: Edward Elgar.

Iansiti, M. and R. Levien, 2004, The Keystone Advantage: What the New Dynamics of Business Ecosystems Mean for Strategy, Innovation, and Sustainability, Boston: Harvard University Press.

Ishii, K., 2004, 'Internet use via mobile phone in Japan'. Telecommunications Policy, 28 (1): 43-58.

ITU, 2002. $3 G$ mobile policy: the case of Japan. International Telecommunication Union report.

ITU, 2003, Promoting broadband: the case of Japan. International Telecommunication Union report.

Jacobides, M.G., 2005, 'Industry Change through Vertical Disintegration: How and Why Markets Emerged in Mortgage Banking’. Academy of Management Journal, 48: 465-498.

Jacobides, M.G., 2008, 'Playing Football in a Soccer Field: Value Chain Structures, Institutional Modularity and Success in Foreign Expansion'. Managerial and Decision Economics, 29: 257-276.

Jacobides, M.G., T. Knudsen and M. Augier, 2006, 'Benefiting from innovation: value creation, value appropriation and the role of industry architectures', Research Policy, 35: 1200-1221.

Jacobides , M.G. and A. Kudina, 2009, 'Industry architectures and globalization: institutional modularity, value chain similarity and ease of foreign expansion', Working Paper.

Jacobides, M.G. and S.G. Winter, 2005, 'The Co-evolution of Capability and Transaction Costs: Explaining the Institutional Structure of Production'. Strategic Management Journal, 26: 395-413.

Katz, M. and C. Shapiro, 1985, 'Network Externalities, Competition and Compatibility'. American Economic Review, 75 (3): 424-440.

Klepper, S. and E. Graddy, 1990, 'The Evolution of New Industries and the Determinants of Market Structure.' The RAND Journal of Economics, 21: 27-44.

Klepper, S. and P. Thompson, 2006, 'Submarkets and the Evolution of Market Structure'. RAND Journal of Economics', 37: 861-886.

Kushida, K., 2007, 'Wireless Bound and Unbound: The Politics Shaping Cellular Markets in Japan and South Korea'. Journal of Information Technology and Politics, 52: 231-254.

McGahan, A., 2004, How Industries Evolve: Principles for Achieving and Sustaining Superior Performance, Harvard Business School Press.

Murmann, J.P. and K. Frenken, 2006, 'Towards a systematic framework for research on dominant designs, technological innovations, and industrial change'. Research Policy, 35: 925-952. 
O'Brien, K.J., 2007, 'Forerunner of mobile Internet, i-mode is fading in Europe'. New York Times, July 17, 2007.

Ozcan, P. and Eisenhardt, K. 2009, “Origin of portfolios: entrepreneurial firms and strategic action.' Academy of Management Journal, 52 (2): 246-279.

Pisano, G. P. and D.J. Teece, 2007, 'How to capture value from innovation: Shaping intellectual property and industry architecture'. California Management Review, 50: 278-296.

Poropudas, T., 2002, 'Austria opens up 3G network without handsets'. Mobile Monday, Sept 25, 2002.

Schilling, M.A. 2000. Towards a General Modular Systems Theory and its Application to Interfirm Product Modularity. Academy of Management Review, 25: 312-334.

Shapiro, C. and H.R. Varian, 1998, Information Rules: A Strategic Guide to the Network Economy, Boston, Mass: Harvard Business School Press.

Sigurdson, J., 2001, 'WAP Off - Origin, Failure and Future'. Stockholm School of Economics Working Paper, 135.

Steinbock, D., 2003, Wireless horizon: Strategy and Competition in the Worldwide Mobile Marketplace. Amacom: New York.

Steinbock, D., 2005, Mobile revolution: The Making of Mobile Services Worldwide. Kogan Page Publishers.

Suarez, F.F., 2004, 'Battles for Technological Dominance: An Integrated Framework' . Research Policy, 33(2): 271-286.

Teece, D.J. 1986, 'Profiting from technological innovation: Implications for integration, collaboration, licensing and public policy'. Research Policy, 15 (6): 285- 305.

Tripsas, M., 1997, 'Unraveling the Process of Creative Destruction: Complementary Assets and Incumbent Survival in the Typesetter Industry'. Strategic Management Journal, 18 : 119-142.

Tushman, M. L. and P. Anderson, 1986, 'Technological discontinuties and organizational environments'. Administrative Science Quarterly, 31: 439-65.

Ulrich, K., 1995, 'The Role of Product Architecture in the Manufacturing Firm'. Research Policy, 24:419-44.

Utterback, J.M. and W.J. Abernathy,1975, ‘A Dynamic Model of Product and Process Innovation'. Omega, 3 (6): 639-656.

Van Impe, M. 2003. Uptake of I-mode is disappointing for KPN Mobile. Mobile Monday, March 4, 2003.

Yin, R. K., 2003, Case study research, design and methods, 3rd ed. Newbury Park: Sage Publications. 
${ }^{\mathrm{i}}$ To illustrate, whereas in Japan i-mode has an active user rate of $89 \%$, in subsequent European deployments this percentage ranged from $0.2 \%$ up to $21 \%$. Most European providers have since phased out the service.

${ }^{\text {ii }}$ During the first stage (2002) of our research, we tried to understand differences in success between the Japanese and European deployment of mobile internet services; in the second stage (2004), we focused on the development of several mobile platforms in the European mobile industry. As it became clear that industry architecture plays an important role in the development of these platforms, we focused our attention on the interplay between platforms and industry architectures, revisiting and expanding our initial data collection. Finally, in 2009 we held additional interviews to get further reflection, particularly on the deployment process in the Netherlands.

${ }^{\text {iii }}$ See the Communication to the European Parliament concerning the common positions of the Council on the adoption of the reform of the telecoms regulatory framework, 17 February 2009,

http://eurlex.europa.eu/LexUriServ/LexUriServ.do?uri=CELEX:52009PC0078:EN:NOT

${ }^{i v}$ The phrasing in the press release was deliberately vague because negotiations about the license were still ongoing.

' One example of a collective marketing endeavor was i-mode's sponsorship of Renault's Formula 1 team in 2004.

${ }^{\mathrm{vi}}$ We would like to thank an anonymous reviewer for prompting this issue.

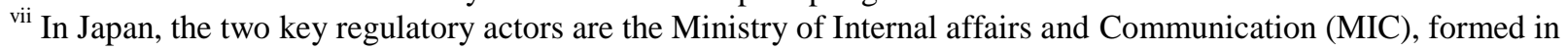
2004 and the Japan Fair Trade Commission (JFTC). Prior to the formation of MIC, telecoms regulation was part of the Ministry of Public Management, Home Affairs, Posts and Telecommunications (MPHPT), formed in 1999. In turn, before that regulation was responsibility of the Ministry of Post and Telecommunications (MPT), which was later subsumed into the MPHPT (ITU, 2002; Kushida, 2007).

${ }^{\text {viii }}$ Dutch telecom regulation is managed jointly by the national regulator OPTA (Independent post and telecommunications authority) and the relevant European Union (EU) bodies. Telecommunications policy is the responsibility of DGET (formerly DGTP), a directorate of the Ministry of Economic Affairs. Allocation of the 3G licenses was done by the Ministry of Transport who, advised by OPTA and NMA (the national competitions authority), decided to distribute these via a competitive auction. Also, EU directives typically inform national policy and regulation.

${ }^{\text {ix }}$ MNP became mandated in Europe only in 2003, as part of the EU's Universal Service Directive.

${ }^{x}$ For example in the UK, total licensing costs amounted to $£ 22.47$ billion and in Germany to $€ 51$ billion (see Binmore and Klemperer (2002) for background information on the $3 \mathrm{G}$ auctions).

${ }^{\mathrm{xi}}$ As a further illustration, when Austrian network operator Mobilkom announced the launch of its 3G network service, it could not offer customers a single $3 \mathrm{G}$ handset, being dependent on timelines of handset manufacturers (Poropudas 2002).

xii As an illustration, in 2007, Docomo's R\&D budget totalled $¥ 99,315 \mathrm{~m}(\$ 845 \mathrm{~m})$; by contrast KDDI’s R\&D budget in the same year was $¥ 2,283 \mathrm{~m}(\$ 23.8 \mathrm{~m})$, and Softbank’s $¥ 833 \mathrm{~m}(\$ 8.8 \mathrm{~m})$; for the GSM operators, Vodafone's R\&D budget in 2007 was $£ 222 \mathrm{~m}$ and KPN's $€ 16 \mathrm{~m}$ (source: annual reports).

xiii Examples of this include music platforms (Nokia ComesWithMusic) that bypasses the mobile operator and are sold directly by retailers or by Nokia itself; another example is Nokia's Ovi platform, which acts as portal to personal content (e.g. contacts, photos, music) as well as third party services.

${ }^{\text {xiv }}$ Examples of this include Vodafone's attempts to introduce handsets exclusively branded with the Vodafone label (Steinbock 2005), as well as other European operators (e.g. Orange or Three) that often co-brand their handsets with the operator logo.

${ }^{\mathrm{xv}}$ Examples of such studies are Ballon (2009) who studies several mobile platforms in relation to business models, and Boudreau (2005) who compares the development of several mobile operating systems platforms. 